\title{
Economic modelling - Beyond isolation and construction. The case of Austrian Business Cycle Theory as presented by Roger Garrison
}

\author{
ROBERT MROZ (1) and LUKASZ HARDT* 주
}

Faculty of Economic Sciences, Warsaw University, Długa 44/50, Warsaw, 00-241, Poland

Received: January 8, 2018 • Revised manuscript received: July 12, 2018 • Accepted: September 21, 2018

(C) 2020 Akadémiai Kiadó, Budapest

\begin{abstract}
The paper explores the nature of economic models. It is claimed that accounting for it along the isolationism-constructivism line is untenable. A more integrated approach is needed, based on the pragmatist philosophical tradition, focussing rather on the modelling process than on the narrower notion of the model. This argument is backed by a case study: analysis of the Austrian Business Cycle Theory (ABCT) as presented by Roger Garrison, which, as is argued, does not fully fit either the isolationist or the constructivist account of models. It is primarily shown by revealing the fact that learning about the world by using $\mathrm{ABCT}$ is not of deductive nature. Therefore, even in the presence of such a strong realistic methodology as the one in the Austrian economics, models used by its adherents are not necessarily perfect isolations. At the same time, this realistic methodology is not in line with the constructivist approach in model-building. The paper should be understood as an exercise in philosophy of economics, namely as an attempt at better understanding of various aspects of economics (here it is models and specifically ABCT) by taking the perspective offered by philosophy of science.
\end{abstract}

\section{KEYWORDS}

economic methodology, economic modelling, Austrian economics, Austrian Business Cycle Theory

JEL CLASSIFICATION INDICIES

B25, B40, B53

*Corresponding author. E-mail: lhardt@wne.uw.edu.pl 


\section{INTRODUCTION}

The literature concerning the nature of models and modelling as a scientific practice employed by economists has grown considerably in recent years (Fullbrook et al. 2009; Kovács 2019; Morgan 2012; Morgan - Knuuttila 2008). This is hardly surprising, given that the lion's share of theorising in economics is done by the way of models. ${ }^{1}$ This fact alone warrants curiosity of philosophers of science as well as practicing scientists interested in methodological issues. While focussing on models they all take the metatheoretical perspective: apparatus of the philosophy of science is used to illuminate some theoretical issues in economic modelling. However, as it is common in philosophy, no agreement has been reached as to merits and shortcomings of different accounts of models, and whether any of them is fit to serve as a guidance to proper conduct for economists. Roughly, these accounts can be divided along the isolationismconstructivism line. However, the borderline is not sharp and there is an interesting discussion on how these two approaches should be understood (Morgan - Knuuttila 2008).

This paper is not meant to serve as an argument in favour of any side. Instead, its aim is to show that both the approaches have important virtues as well as some crucial deficiencies. In doing so we subscribe to a typical way by which philosophy of economics is undertaken: rather than suggesting how economics should be done, we try to understand a given research practice here modelling and in particular the Austrian Business Cycle Theory (ABCT). Consequently, there seems to be a need either to exploit strong sides of both of them or to adopt some more pragmatic stance that will not be focused so much on the proper description of a model, but will rather try to account for more broadly conceived scientific practice of economists (i.e. modelling). Therefore, the aim of the paper is more that of a critique, so a negative one. Nevertheless, the closing remarks are devoted to outlining (if only in broad strokes) of what we think could be a proper remedy to the problem. This is done as follows. In Section 2, we describe Robert Sugden's constructivist theory in the context of a related account laid out in Grüne-Yanoff (2009) and show that, while such theories seem to provide a good description of a number of modelling strategies employed by practicing economists, they rest too strongly on the notion of intuition, thus blurring an important aspect of model-based informative inference. In Section 3, we look at isolationist proposition, both in Mäki's and, especially, in Cartwright's version (they do not differ much, but it is important to note the differences). The critique of this theory is the starting point of many constructivist endeavours, so many of its shortcomings are already well known (Grüne-Yanoff 2009, 2011; Knuuttila 2009). But, of course, there are also replies to these criticisms and the debate is ongoing.

Therefore, in Section 4 we would like to present a different argument that shows what the problems of realistic isolationism are - an argument by the way of example. The model chosen as an example is ABCT as laid out in Garrison (2001). First, we show that the name "theory" is misleading when applied to this specific presentation of ABCT, which surely can be described as a model, even if it does not use standard mathematical tools of mainstream economics. Second, it is crucial to note that ABCT rests firmly on the realist notions as the Austrian methodology is

\footnotetext{
${ }^{1}$ The interest in models on part of philosophers of science can also be seen as an instance of a general move from doing more normative philosophy to looking at scientific practice (Hoover 2013). Since scientific practice in economics involves models, descriptive philosophy of economics has to take it into account.
} 
a strictly realistic one. ${ }^{2}$ Therefore, it should be instructive to see how the isolationist account of models copes with accounting for the structure of ABCT and for inferences based on it. If there is a problem for isolationism in accurately describing any of these aspects - and we intend to show that there is a problem with treating model-world inferences as deductive - it means that the theory does not fare very well even in the most favourable circumstances. ${ }^{3}$ In Section 5, we consider how this could be amended. There are, roughly speaking, two ways of proceeding. Either one can hope to somehow integrate the notion of isolation with a broader notion of inference that could incorporate some forms of induction (in fact, Mäki (2009) tries to do just that, but he is concerned solely with Sugden's account and his argument does not address the Grüne-Yanoff's theory), or one may accept some pragmatic theory of modelling that shifts focus from models themselves to the practice of modelling, e.g. along the lines of Knuuttila (2009) and Morgan (2012). We argue that this view has a strong philosophical foundation dating back at least to Wittgenstein's Philosophical Investigations (1953), having support of many great philosophers outside the narrow field of the philosophy of economics. This indicates that this may be a way out of the discussed problem. Conclusions follow in Section 6.

\section{CONSTRUCTIVISM IN MODEL BUILDING}

Constructivists observe that a lot of models are not primarily driven by the real-world considerations, but are rather constructs that were conceived independently of any real-world phenomena. Thus, they reject the notion of isolation as foundation of modelling. One example is Robert Sugden's $(2000,2009)$ account of models as credible worlds that do not need to involve any isolation or abstraction from the features of reality. Indeed, they do not even need to resemble our world in any particular way, and nevertheless they are able to provide a valuable insight. This is a very imprecise characterisation - that will be developed below - but it is already clear that constructivism does not require any form of realism, even though it does not preclude such a worldview. ${ }^{4}$ But if one wants to state some conclusions about the world after one examines such a constructivist model, deduction is not a viable option - there is no straightforward model-world link that would secure its validity. ${ }^{5}$ As will be discussed in more detail in Section 3, the notion of deduction employed here is only the most general one - that is,

\footnotetext{
${ }^{2}$ The terä "realism", as will also be discussed later, refers here to the basic formulation of scientific realism, i.e. there exists a mind-independent reality and the scientific models are able to represent processes and mechanisms obtaining in this reality.

${ }^{3}$ Obviously, accounts of modelling discussed here focus primarily on what is usually called the "mainstream" economics. But, as we intend to show, this does not preclude using a heterodox model such as ABCT as a test bed. Mäki (1992b) himself discusses the Austrian economics as inviting realistic reading as an isolating theory.

${ }^{4}$ Thus, one reservation is in order here, namely that the constructivist stance discussed here does not necessarily imply the Constructivism with capital 'C', namely a world-view according to which "the world" is a consequence, rather than a cause, of scientific representation or, in other words, that "the world" is constructed rather than discovered (Knorr Cetina 1998). The same holds, for instance, for fictionalism in philosophy of modelling, which is not a position in metaphysics, but rather a view in the methodology of model building meaning, for example, that one can have fictional representations of the real mechanisms.

${ }^{5}$ Levy's (2012) idea of the whole-cloth fiction for an interesting discussion on how the constructivist models can be confronted with reality.
} 
deductive reasoning is such that given true assumptions necessarily produces true conclusion. We do not mean anything more specific by this term. Constructivists need to rely on one form or other of inductive inferences - taken here to be a simple antithesis of deduction as defined above, so that they encompass every type of fallible inference (Niiniluoto 1998) -, a feature that is often criticised by their isolationist peers.

We take Robert Sugden's "credible worlds" theory to be representative of many crucial aspects of constructivism, although, as it still holds to some realist notions (such as "resemblance" of the model to the world), it is not the radical version of the stance. That is why we also consider a more hardline "minimal model" theory of Till Grüne-Yanoff (2009), who holds that no relation of resemblance is needed for the model to be informative, but at the cost of it bearing relatively little information. However, to get a starting point for the discussion, one first has to begin with the new classical exposition of constructivism in model building, namely Sugden's approach. His example aims at demonstrating that economists do not isolate. He shows this by referring to the "checkerboard model" of racial segregation devised by Schelling (1978). The model consists of a checkerboard with white and black pawns deployed randomly. The pawns symbolise people and their colours symbolise races. The pawns have only one "preference" they do not want to live in an environment where their colour is heavily outweighed by the other - which reflects the idea that people generally do not want to live in strongly racially segregated areas. This relatively uncontentious assumption leads to surprising results, if we specify the following rule: whenever a pawn is "not content" with its neighbourhood, it moves to the nearest free square. The result is a strongly segregated distribution of white and black pawns. Sugden $(2000,2009)$ does not believe that such a model could be accurately described by isolationists. "Just what do we have to seal off to make a real city - say Norwich - become a checkerboard?" (2000: 127) So, he thinks that Schelling constructed his model instead of isolating some aspects of reality. This point is further developed by reporting the account of modelling process given by Schelling himself (Sugden 2009). It turns out that he started writing pluses and minuses on a piece of paper trying to come up with some good example to tell his students and noticed that every time he starts to combine these signs, patterns of segregation emerge. Attracted to the idea, he wanted to work in three-dimensional space that would be easy to operate, and that is why he chose a checkerboard. As we see, no feature of reality that is relevant for the interpretation of the model was a driver for Schelling's actions - he was just concerned with what setup would be the most practical. Therefore, as argued by Sugden, it was not an intention of the modeller to isolate anything. Even more, it was not his intention to actually represent any part of the reality (in this case, a city), as the interpretation was given to the model ex post (and then, it could be formulated in terms of the mechanism that may operate in actual cities). Therefore, despite the claims by Mäki and Cartwright, Sugden feels free to conclude that isolation is not what economists usually do when they build a model. ${ }^{6}$

Sugden prefers to think about models as parallelling the real world instead of originating from it by isolation. To capture this idea, he coined the term "credible worlds". A model functions as a credible world when it is not intended to represent, instead being a depiction of

\footnotetext{
${ }^{6}$ It is worth noting that, while we take isolation to be the foundation of Cartwright's work, her writings also point in other directions as to the nature of modelling. For example, in some of them (1999a, 2010) she mentions "models as fables" which are intended to present some moral. Still, given her extensive work on Galilean experiments, there is nothing contentious in taking the notion of isolation as fundamental to her views.
} 
some counterfactual situation that could obtain in reality provided a credible world is sufficiently similar to our world. According to the author, this relation of similarity or "salience" (or "credibility", for that matter) cannot be formulated in mathematical or logical terms, depending instead on the subjective judgement of the modeller, and thus, giving basis for inductive inferences. It is visible that any such inference requires additional hypotheses to provide insight as to the properties of reality, for any consideration of similarity, salience or plausibility is largely independent of the structure of the model itself (hence, subjectivity). What is the nature of these inferences? Sugden claims that it is best to see them as abductions, also called "inferences to the best explanation". 7 The idea is as follows. If the model is not necessarily constructed so as to reflect some isolated aspects of reality, the modeller can first "play" with his construction, uncover its mechanisms, and derive results. Then, when this part of work is done, researcher may look at the world and find situations in which events that occur resemble the events that result in the model. If these two types of events are really similar, one can, via abductive reasoning, postulate that the causes also should be similar. The immediate consequence is that the more similar the model is to the world, the more informative it is. Of course, one has to remember a rather particular meaning of "similar" in the context where models are not meant to represent. In such context "similar" surely does not mean "realistically depicting/describing", but rather "credible/plausible" in the sense that the fictitious world described by the model could be real.

Inspired by Sugden, Grüne-Yanoff (2009) sets out to demonstrate what we can learn from the models even if they do not serve as proper surrogates and we cannot point to their specific connection with reality. A minimal model, which is a fundamental building block of his account, is defined as a model that needs not to bear any resemblance to the world, does not isolate anything, has a formal structure and a distinct interpretation in terms of some imagined world; its representational function as a surrogate is, at best, only declared and not specified. To "learn" from a model means to have one's degree of confidence in certain hypotheses concerning the world changed. Connection to Sugden's view is straightforward - Grüne-Yanoff thinks of models as constructions that can result from thought processes unconcerned with any real causal mechanisms. His account also needs to address the question of how we can get to know anything from such constructions, but, instead of settling for Sugden's credibility and induction, Grüne-Yanoff sees them as far-fetched. According to him, Sugden envisions credible worlds as providing basis for inference from a specific model to general hypotheses about the world, which he sees as too strong of a notion. In his view, evaluation of credibility depends too heavily on particular features of a given situation and Sugden (by saying that to proclaim a model credible is to claim that similar causal mechanisms operate in a model and in reality) implicitly assumes stability and universality of causal mechanisms, which brings him too close to the isolationist stance. Furthermore, even if a model is deemed credible, there most probably exist substantial differences between it and the world. This raises a question: how could a credible model justify using propositions about causality, which have been established within this model, in relation to the world? Even if we, like Sugden, want to use a conventional induction here, we need to show first that these differences do not matter to the validity of inductive inference. On GrüneYanoff's account one cannot try to remedy this problem by tying credibility to some kind of

${ }^{7}$ That is contrary to Mäki's (2009: 38) claim that they are inferences to a possible explanation (italics in original). However, as we treat them as abductions, we just follow the meaning of abduction from the logic where it stands for "inferences to the best explanation" (Magnani 2001). 
resemblance or truth, as such notions are discarded at the outset by the use of the concept of the minimal model (which Grüne-Yanoff claims to be the only notion able to capture those properties of models that are relevant to their use in science and common across all disciplines).

How, then, are such credible minimal models useful or, in author's own words, what can we learn from them? And how can the inference look like if it is neither deduction nor Sugden's abduction? Grüne-Yanoff claims that they are useful in assessing propositions about impossibility (and, conversely, about necessity). If, say, we strongly believe that it cannot be so that " $p$ and not-q", and we have a credible model - that we cannot just disregard - which says that "p and not-q", we have to at least lower our degree of confidence in the proposition of "not ( $p$ and not-q)". Therefore, one can learn something just from the fact that some models, namely the credible ones, exist. By extension, this view also supplies a tool for evaluating the "goodness" of models - if there is no impossibility claim that a given model could contradict, then it affects noone's confidence level and is useless as one cannot learn anything from it. ${ }^{8}$

Grüne-Yanoff's idea is an interesting one that tries to capture the essentials of scientific modelling. The minimal model is designed so as to reflect only the ubiquitous characteristics of the models, and characteristics an entity must have to be even considered as a model. Also, his critique of Sugden's use of induction is supported by what we consider conclusive argumentation found in Cartwright's paper (2009). At first, she notes that Sugden, by referring to the examples that concentrate on one or few factors acting "in isolation" (as is the case with Schelling's model) and by assuming that observing a factor "in isolation" can be helpful in understanding non-modelled or non-experimental outcomes, is in fact relying on the logic of causal relations' characteristic of isolationism. ${ }^{9}$ The problem is that from such models we cannot generally learn anything of value about causality. The reason for this is that economic models, in contrast to properly specified experiments in physics (Galilean experiments, as dubbed by Cartwright), are usually overconstrained (also Cartwright 1999a, 1999b, 2007). Overconstraint means that apart from assumptions necessary to isolate the causal relation in question (and therefore justified), the model contains additional assumptions needed for it to work and produce any results. ${ }^{10}$ In economics, these are most often assumptions needed to make a model mathematically tractable, such as perfectly divisible goods, continuity of certain functions, completeness of preferences, or specific assumptions about expectations (adaptive/rational)

\footnotetext{
${ }^{8}$ For a view that one cannot learn from the minimal models, see Fumagalli (2016).

${ }^{9}$ Other than that, Sugden tries to distance himself from the logic of capacities as far as possible.

${ }^{10}$ According to Cartwright (e.g. 2010: 3), Galilean experiments isolate a single factor so that an experimenter can observe its natural effect when it operates "on its own" and "without impediment". The difference between such experiment and an analogous model ("Galilean thought experiment" (ibidem)) is that in the experiment "the effect is produced in accord with the laws of nature", while in the model "it is the principles built into the model that determine what the effect must be" (ibidem). This helps to clarify one point: while in many physical experiments an experimenter really seems to be conducting only abstractions ("Aristotelian idealizations" (Frigg - Hartmann 2012)), one could argue that in economic models assumptions may involve not only abstractions or, more precisely, omissions (e.g. no transaction costs), but also additions or distortions ("Galilean idealization" (Frigg - Hartmann 2012)) - putting some characteristic into the model that is not present in the world (e.g. full rationality or perfect information). Such additions may be seen as giving rise to the problem of overconstraint discussed in the text. On the other hand, it is possible to argue (Mäki 2009) that such additions are in fact abstractions by omission, e.g. that perfect information is in fact absence of imperfect information. While such reformulation helps to simplify the notion of Galilean thought experiment, the problem of overconstraint of course still stands.
} 
(Alexandrova 2006). Overconstraint is a problem when one cannot just drop such assumptions as they are indispensable for the model to work and, as we very well know, this is the usual situation in economics. In such case no causal mechanism present in the model can be safely generalised to the real-world situations because there is no way to know if the model would predict such mechanism should those additional assumptions be removed. ${ }^{11}$ Cartwright sees a twofold reason for this unlucky state of affairs. First, the set of unequivocally accepted principles that form a suitable basis for deduction is very small in economics. Second, relations between economic variables are very different from the ones usually studied by the way of Galilean experiments - in mechanics every factor is a force that can be summed up with all the others, while in economics everything depends not only on "forces", but also on structural connections (e.g. on institutions), which make combining causal factors to obtain a final outcome extremely hard if not downright impossible. All in all, this amounts to the very wellknown problem of unrealistic assumptions and deciding which models are unrealistic in a right, and which - in a wrong way (Mäki 2001).

Having said this, Cartwright notes that Sugden does not want to argue for constancy of causal relations, but to conduct a "careful induction from one case" (where induction is understood in narrower sense as an inference from a limited number of cases to a general conclusion). Indeed, this seems to be the case: having established that the model is credible, a researcher in Sugden's account has a basis to state some general hypotheses about the world. But there is an immediate problem with such approach: one should not use induction where there exist salient differences between the inductive base and the target, which is almost always the case in economics, especially when one explicitly discards resemblance understood as realistic description, as Sugden does. This is the point at which Cartwright's and Grüne-Yanoff's critiques meet.

It follows that Cartwright's argumentation does not say anything about the relevance of Grüne-Yanoff's conception. Yet there are certain aspects of it that warrant closer attention. First of all, if the notion of the minimal model, which he seems to treat as the maximal uncontentious notion of the model, ${ }^{12}$ supports only the kind of learning described by the author, it is hard not to see that it is really not much. In empirical matters, economists still cannot come to the conclusion about causes of the Great Depression, not to speak about the crisis of 2007-2008. In theoretical matters, there are of course axioms of decision theory that form the basis of microeconomic theorising, but we know very well that these axioms do not generally hold in reality. In macroeconomics, things are even worse, as virtually every theoretical proposition faces opposition from representatives of other "schools". One could name examples endlessly but it is enough to note, as Cartwright (1999a, 1999b, 2007, 2009) does, that there is a striking

\footnotetext{
${ }^{11}$ For the same reason, overconstraint also causes problems when models are to represent theories (Morrison 2007: 203).

${ }^{12}$ By "uncontentious" we mean that if one would want to add anything to a minimal model defined as above, one would end either in some kind of constructivist Sugden-like position, or in some kind of isolationst stance. The whole difference between Grüne-Yanoff and Sugden is contained in this notion (note that both use the notion of credibility in the same manner), so it is easy to see how adding new elements could lead one to ending up in a "credible worlds" view. On the other hand, if the minimal model is defined so as to connect any kind of practice employed by the modellers in various disciplines, it is certainly possible to add notion of isolation to its description (because it is used in physics). Therefore, the concept of the minimal model can be viewed as a maximal notion of model to which adherents of various methodological positions can agree.
} 
scarcity of universally accepted propositions in economics. And if a sentence $p$ is not generally accepted and allows exceptions, then the degree of confidence in impossibility of non- $p$ is zero for an impartial observer not immersed in teachings of any particular "school". But suppose, we are thinking about a practicing economist who holds some strict convictions about matters that can be contentious in the whole field. Then, examining the results of a model that one deems credible and seeing that they run counter one's beliefs about impossibility of something, may (and should) legitimately influence one's degree of confidence in such impossibility claim. This is of course an implementation of Bayes' inferential rule. But there is a twofold problem with such account of model-world inference.

Firstly, the reasoning here is informal and there is a substantial degree of uncertainty concerning inferences. Every researcher comes from a different background, has different presuppositions according to which she asserts validity of results and, hence, each one will be persuaded by different kinds of "credibility" (for a short taxonomy of the notions of credibility see Mäki 2009). What is more, in a field seemingly dealing with open and complex systems (Lawson 1997, 2003, 2009), in which theories and models are, at best, capturing only limited aspects of reality, ${ }^{13}$ there exist various mechanisms to defend oneself from accepting conclusions that seem to contradict one's beliefs. These include tinkering with ceteris paribus clauses, refusing to accept some assumptions or econometric methods, etc. This is not to say that economists have a habit of dismissing evidence that could undermine their beliefs. This is also not to say that the pragmatic aspects of doing science, such as rhetoric and even eristic, should be disregarded in trying to account for scientific practice. This is just to say that if one breaks all deductive links between the model and the target, it is hard to see how one could get a lot of substantial and interesting knowledge about the phenomena under study, and knowledge with a legitimate claim at being more or less universally accepted. Because so many different things can be credible to many different people, credibility alone seems too weak to provide grounds for the widely accepted economic claims. Of course, this is only a problem if one wants to have more such universally accepted claims. It seems, however, rather straightforward that this should be a reasonable requirement for science.

This is related to the second point, which bears heavily not only on Grüne-Yanoff's, but also, and maybe foremost, on Sugden's account. Both authors seem to leave a lot of space for intuition in their respective theories, the former via use of the notion of credibility together with an informal Bayes' rule, the latter via the credibility and explicit claims that subjective judgements of similarity and salience matter in transporting conclusions from the model to the target system. The problem with intuition is that it varies wildly across persons. That these matters can be acute even in a circle of trained professionals is well attested by arguments in ethics. ${ }^{14}$ Therefore, if both Sugden and Grüne-Yanoff want to rely heavily on researcher's intuitions in gathering knowledge about target systems, we are forced to conclude

\footnotetext{
${ }^{13}$ Of course, this claim makes sense only if one is willing to accept some form of realism. If not, instead of capturing aspects of reality, one may speak of building a coherent body of knowledge or of persuading her peers, etc.

${ }^{14} \mathrm{An}$ immediate response could be that economics is much more "scientific" than ethics. That is probably right, given the common (one is tempted to say "intuitive") sense of "scientific", but still, given such common understanding, it is certainly nowhere near as scientific as physics and is, as noted above, an area of constant debate about virtually every aspect of the field.
} 
again that wholesale rejection of deduction would result in a disjointed body of contentious knowledge.

But suppose that a lot of intuitive insights would be uncontentious to "insiders", i.e. trained economists familiar with the basic propositions, cutting-edge research, common methods and modes of reasoning. Then it would arguably be easier for common intuitions to produce a more uniform set of scientific propositions. But then again, it risks coming at a cost. Because what is the basis of accepting someone to the community of experts? If it is all of the above characteristics related to education, then we can safely say that there is no homogenous community that would share largely the same intuitions, as there are numerous examples of economists who received formal economic education and yet drifted away towards, e.g. the Austrian economics, motivated by their very different methodological or political views. And the Austrians certainly do not share many convictions with the "mainstream" economists. So, it seems that for the credible worlds coupled with subjective and intuitive reasoning to provide knowledge accepted more or less generally across the scientific community, one would have to restrict the notion of scientific community so that its members would be more likely to share intuitions and notions of credibility. One such restricted area is, of course, mainstream economics. This restriction could be based, for instance, on whether an economist, by and large, accepts basic tenets of axiomatic microeconomics and central assumptions of macro theory, as well as popular research methods such as econometrics. But clearly this is a weird restriction in a sense that it seals the scientific community off of any heterodox influence. Certainly, diversity in science is not something to be afraid of, rather something to be cherished as a main driver of theoretical as well as applied advancement. Even if one is sceptical about the idea of scientific progress, it is hard not to see the fact that many interesting (even if not "better", as the notion of betterment is exactly what is discarded by anti-progressivists) theories came to life as responses to the mainstream ones. ${ }^{15}$

To recapitulate, the claim here is that (1) if constructivism as defined above is right, then all deductive model-target links are severed; (2) if deductive links are severed, then they are replaced by considerations of model credibility or similar and by subjective, intuitive judgements; (3) such considerations and judgements vary greatly across people, even trained specialists; (4) there are not many universally accepted propositions in economics and it would be a good thing to have more of them; (5) considerations of credibility and subjective judgements cannot provide widely accepted claims in economics unless the relevant group of economists is defined so as to ensure some uniformity of intuitions; and (6) this definition would be overly restrictive. Therefore, there is a problem with constructivism.

One extremely important point is warranted. It may well be true that Sugden's and GrüneYanoff's accounts of modelling are descriptively correct, i.e. that economists really disregard notions of isolation in their practice and focus instead on creating constructions which are given (or not) some interpretation ex post and that the model-target (or model-world) inferences are similar to what is described by two authors. Therefore, argumentation presented above is not meant to be seen as a report from field observations of economists. It is rather intended as a normative critique. It follows that if Sugden and Grüne-Yanoff are indeed descriptively correct, then this normative critique becomes directed at economics itself, dictating an unfavourable

\footnotetext{
${ }^{15}$ Indeed, one may argue that economics itself started this way, for Adam Smith's "The Wealth of Nations" can be considered a lengthy response to the mercantilist fallacies.
} 
view of its current state. Therefore, we tend to side with Cartwright when she says that if economics fails to live up to demands of her theory, it is economics' problem. ${ }^{16}$ So, if our claim is at all correct, one has to look for a way to incorporate deductive reasoning into the modeltarget inferences. Of course, isolationism tries to do just that. The relevant question is: is it successful? We focus on isolationism in the next Section.

\section{ISOLATIONISM IN MODELLING}

To use Mäki's (2009) terminology, isolationists see models as surrogate systems, a sort of "standins" for reality, thus being devices by way of which economists want to acquire knowledge about the real world. Of course, this means that isolationism commits its proponents to scientific realism, i.e. the belief - in its basic form, as there are various much stronger versions of the doctrine - that there exists a mind-independent reality ${ }^{17}$ that is, at least in principle, truthfully describable or explicable by science. ${ }^{18}$ Therefore, on this view, scientific models are capable of representing real processes and mechanisms. An important feature of this approach is that inferences from the model to the world are of deductive nature, as the crucial (isolating) assumptions have to be "realistic" for the model to fulfil its purpose of being a surrogate. It is exactly this link between the model and the world that allows transferring intra-model deductions more or less directly into the reality.

Two clarifications are in order. First, "realisticness" of isolating assumptions does not mean that they have to map the world exactly to the model. They can well be very unrealistic in assuming, say, no transaction costs or static institutions. Realisticness is best understood as relative to the aim of the model, i.e. isolating assumptions have to properly isolate unimportant (in view of a specific aim) factors in order to put emphasis on crucial explaining items, even if assuming away such factors is unrealistic in the conventional sense of the world. Second, the claim that the nature of the model-world inferences is deductive is meant to employ only the basic, most general sense of deduction, namely a kind of inference that, given true assumptions, necessarily produces true conclusions (deduction is truth-preserving). Any narrower understanding of deduction is not needed in this context, as what is essentially said in the preceding

\footnotetext{
${ }^{16}$ Cartwright (2009) goes even further, claiming that she does not see any hope for the field to live up to the standards of her isolationist views and, consequently, of it ever becoming a "mature" science. We would not be so harsh. In this respect our approach sits closer to the one of Mäki, who sees the method of isolation as by and large descriptively accurate. As we show in Section 3, there are problems with such a view (correctly pointed out by Cartwright and, to some extent, by Lawson), but that does not mean that deductive reasoning has to be abandoned - given the views on induction and intuition expressed above, it would really mean a dismal future for economics.

${ }^{17}$ As noted by Mäki on numerous occasions, in the domain of economics, scientific realism cannot be limited only to the mind-independent reality, as economics inherently deals, among others, with beliefs and values. We accept this reservation as important, however it has no bearing on the discussed issue.

${ }^{18}$ Of course, such crude formulation of realism in philosophy of science combines ontological (the claim that the world exists) and epistemological (the claim that the world can be truthfully described by science) theses. The epistemological claim is termed as "weak epistemological realism" by Deichsel (2011). There is also a strong version, according to which scientific theories not only can be true (in the sense of classical definition of truth), but largely are true about the world. But this strong version is not the one supported by the realists such as Mäki or Cartwright, who are clearly aware of the fallibility of science.
} 
paragraph is that if we have conducted our isolation procedure entirely correctly, conclusions of the model apply directly to the world. ${ }^{19}$ In other words, if we were able to perform an ideal isolation (the assumption), the results in the model would necessarily transfer to the world without any mediating - and possibly fallible - inference (the conclusion). Of course, even if one accepts the isolationist stance, constant revision of scientific results means that such ideal isolation is never achieved. Therefore, "pure" isolationism is an ideal that could (provided it is acceptable) serve rather as a normative criterion for evaluation of models than as an entirely true description of scientific practice. ${ }^{20}$ This does not preclude serious consideration of isolationism as such description, provided only that we see as reasonable the claim that economists could be applying isolation in their model-building, even if this application is not ideal. As will be presented below, the answer to the question of whether we can view model-building as involving deduction hinges precisely on whether conditions that give rise to this non-ideality preclude successful isolation once and for all.

Proponents of such an isolationist account of models postulate that models are similar to experiments conducted by physicists (dubbed "Galilean experiments" by Cartwright (1999a, $1999 b, 2007,2009,2010$ ) in that they are set up to isolate the relevant causal mechanism while keeping every other mechanism out of the model. ${ }^{21}$ Such causal mechanism, "capacity" in Cartwright's (ibidem), “tendency" in John Stuart Mill's (1843) terminology, is called like this because in reality there are multiple causal factors operating simultaneously and we do not generally expect an experimental result to be replicated in the real world. But the lack of a precise quantitative result does not preclude us from claiming that the factor in question operates - we just need to say that it contributes to the overall outcome, without specifying what this overall outcome will be (Reiss 2008: 267). Both models and experiments do that, the crucial difference between them being that the latter isolate capacities dictated by nature (at least in the clear-cut example of physics) and the former isolate whatever is dictated by their assumptions.

In practice of model building this method allows modellers to study a particular causal mechanism operating in reality by postulating the following steps. First, one has to choose a real target system. Second, by applying isolating assumptions to this system, one strips the target off of its irrelevant features, thus obtaining a model. Then, it is possible to see the effect of a given mechanism. Because the model was obtained without altering any features of reality relevant to the mechanism under investigation, the causal factor in the model (the capacity) can be seen as a 1:1 representation of the mechanism working in the real world in the sense that it resembles the real process and is directly applicable to reality. This is why isolation is so tempting. Of course, in practice it is very hard to know beforehand which aspects of reality are irrelevant to the question at hand, so isolation in economics may, at best, involve countless trials, conducted until

\footnotetext{
${ }^{19}$ Referring to the most general understanding of deduction means that we do not subscribe to any of the more specific treatments of deductive logic, for instance, in the works of Frege, Russell, Whitehead, Hempel, and Oppenheim, and thus, the model-world deductive inference is to a large extent different from the one postulated by the deductivenomological model of scientific explanation. Thus, the notion of deduction in the entire paper is used in its most general sense, just meaning that whenever the premises are true, the conclusion must also be true.

${ }^{20}$ This point, mentioned also, albeit slightly differently, by Grüne-Yanoff (2011), is part of the conclusion of this paper and is developed at the end of Section 4.

${ }^{21}$ For a view that there is no possibility to idealise the target system by neatly isolating away irrelevant features, see Rice (2018).
} 
we find the best combination of assumptions. ${ }^{22}$ Nevertheless, even if pure deduction would prove impossible (this is the gist of basically all constructivist critiques of isolationism), it is crucial - especially in light of the discussion in the previous Section - that isolationism stresses the importance of striving for this ideal and away from the blurry notions of intuition and induction.

Isolationism is more convincing than constructivism in that it does not postulate any vague notions related to the nature of inference, relying instead on formal reasoning procedures. But this same characteristic is also a problem for the account, as attested by numerous arguments pointing to the fact that proper isolation in economics is unfeasible (apart from what was mentioned before, see Hausman 1992; Lawson 1997, 2003, 2009; Knuuttila 2009, etc.). In fact, even Cartwright, a prime figure among isolationists, does not see any bright future for isolation in the economic theorising. The reason for this was already stated - overconstraint (Cartwright 2007, 2009). ${ }^{23}$ Lawson (ibidem) connects this conclusion to the openness and complexity of the world, features one cannot abstract from if one wants to explain anything. Yet these features are the ones that do not let isolation work.

We said earlier that the constructivist account of modelling may be largely accurate by description. But what if one takes under consideration a non-mainstream model? A model which derives from a tradition deeply connected with the realistic outlook? Would it not somehow constitute a different kind of support for isolationism? Well, it certainly might, if it turns out that it is properly characterised by isolationism even if mainstream models are not. On the other hand, if it so happens that there are some problems in describing this model with the use of the isolationist notions, it would cast serious doubt on the descriptive ability of this theory. So, let us consider such a model.

\section{AUSTRIAN BUSINESS CYCLE THEORY (ABCT) - A CASE FOR ISOLATIONISM?}

ABCT was first proposed by Ludwig von Mises in 1912. It was based on the capital-theoretic insights of Eugen Böhm-Bawerk and on the work of Carl Menger, Mises' teacher. It took its fully developed form in the writings of Friedrich August von Hayek $(1931,1941)$ and for a short period of time was considered a serious rival for Keynes' views expressed in The General Theory. After Keynes and his adherents managed to convince politicians and the general public about the superiority of their theory, the Austrian view became very niche. Currently, the Austrian economics, of which ABCT is the most discussed part, remains a heterodox school of thought, although it garnered some limited attention in the aftermath of the economic crisis of 20072008. Because of the realistic convictions of the Austrian economists, resulting in hostility

\footnotetext{
${ }^{22}$ This bears certain similarity to the robustness testing.

${ }^{23}$ In her own words: "Nevertheless, rigorously deriving a result in a model is supposed to provide prima facie evidence in favour of that result. My concern is about just this relation of evidence to hypothesis. To the extent that the derivation in a model makes essential use of non-Galilean "idealising" assumptions, then I do not see how the fact that the result can be derived in such a model can provide any evidence at all for the hypothesis" (1999b: 24). It is, however, interesting to note that some of her remarks seem to indicate that isolationism should be supported by Aristotelian notion of "nature of things", its future, also in economics, could be brighter (1999a: 83).
} 
towards "unrealisticness" of the mainstream models, and of methodology resting on a general claim that economics can (and indeed should) be a deductive science, ABCT should provide a good test for the basic tenets of isolationism, most importantly - for the claim that isolation involves deduction.

We do not want to dwell here on the complexities of the actual economic content of the theory nor on the whole body of the Austrian methodology, but several remarks seem necessary. First of all, the name: "Theory" is not the same thing as "model", is it? Even if this is true, it is tempting to just assume the whole problem away by noticing that the terms 'model' and 'theory' have been widely used as interchangeable in the profession" (Leijonhufvud 1997: 193). Of course, this is not a solution from the point of view of a philosopher (although, admittedly, the boundary between models and theories is very hazy (Frigg - Hartmann 2012)). Going further, it is important to notice how these terms are used casually in the standard textbook expositions of fundamental building blocks of economics. For example, relationship between, say, the Real Business Cycle Theory and its textbook presentation is such that there is just talk about "baseline", "specific", or "general" cases of the "model" and not "theory" (Romer 2006, ch. 5). Roughly, a specific instantiation of a theory could be considered a model in such context. What is presented by Garrison (2001) - whose presentation is our focus here - is undoubtedly a specific instantiation of ABCT, formulated with the help of graphs and some "mainstream" concepts usually absent in the Austrian literature. The use of these new concepts also points to a certain educational aim of the author - to speak to the community of economists at large in order to familiarize them with the Austrian economics. Therefore, Garrison's model can also be seen as an expository device. This would mean, first, that what is presented by Garrison is a reinterpretation of the writings of Mises and Hayek intended to have a pedagogical value and, second, that incorporation of these new elements bestows on this exposition a certain degree of independence from the original theory. The first point is tangentially related to the ideas of logical positivists (Carnap 1938), who saw models only as superfluous devices of pedagogical or psychological value that cannot add anything of substance to the theory. Of course, they restricted their focus to the formal theories expressed by the way of logical and mathematical calculus, but we only intend to underscore the analogy. Therefore, this model could be seen as a specific, graphical representation of the theory. The second point expresses the claim that Garrison's framework is not exactly superfluous. One way the model can be viewed as partly independent of the theory and as adding something is when it simplifies the theory that is too complex to handle (Apostle 1961). The Mises-Hayek theory of fluctuations is not too complex for its authors to handle in words, but proves hard to formalize with the use of standard tools of modern economics. Therefore, Garrison uses concepts such as production possibility frontier (PPF), which were not employed originally, to make the basic ideas of ABCT tractable in graphical form. The combination of pedagogical purpose and partial independence suffices to see Garrison's exposition as a model (Frigg Hartmann 2012), even if, by virtue of a long-standing tradition of the Austrian school, it is still called "theory". In what follows, we will therefore allow ourselves to use terms such as "ABCT" and "model" interchangeably.

Second, the general methodological approach of the school is very different from the one of the mainstream economics (even if one does not think there exists only one "mainstream approach"). The Austrians traditionally think of economics as a purely deductive discipline and, therefore, claim that it is impossible for any evidence to truly contradict a theory that has been 
deductively derived from valid assumptions (Mises 1957). The strictest version of the doctrine claims that only one axiom - "Man acts" - is needed to derive the whole body of economic knowledge (Mises 1949). ${ }^{24}$ This proposition, forming a foundation of the so-called praxeology ("the study of human action"), is a very interesting one that warrants great interest in its own right, but it could also pose problems for the argument advanced here. For what is the point in applying the methodological theories discussed here to a model based on such methodology, when they were clearly developed with completely different approach to economics in mind? The answer comes down to noticing that using ABCT and accepting its inner workings does not require any special commitment to the most contentious aspects of the Austrian methodology, as is proved by the case of Hayek, who distanced himself from praxeology and yet was the prime figure in developing the Austrian capital theory and the model of business cycles. So, there is no need to treat $\mathrm{ABCT}$ as requiring a very distinct, maybe even a suspicious methodology, which allows us to analyse it using the tools of isolationism. What the ABCT does require is a realist world-view, which further helps to establish the case for it being a suitable workshop for isolationist propositions.

That the flavour of the theory that is decidedly realistic is visible when one recants its origins. Mises' initial idea was deeply grounded in Menger's explanation of the origin of money as a social institution - an exercise in realism par excellence, further evidenced by Menger's insistence on causal processes in his explanations, which is consistent with our characterisation of realism at the beginning of Section 3. In his book (1912), Mises went as far as he could to integrate the theory of money and banking so that they could form one general theory of value and prices (Hülsmann 2007: 212) - that was his aim from the outset. And from the outset he was convinced that his account would be insufficient - "The greatest difficulty I faced in the preparation of the book was the fact that I meant to give special attention to merely a limited part of the total scope of economic problems." (ibidem, 212-213). He wrote that it was his intention to prove that the theory of money, seen by many as distinct from economics proper, is in fact a crucial part of the science of economics, and he began this task with an analysis of the nature of money itself (ibidem, italics ours). All this speaks to the fact that the explication of the real-world phenomena was always the primary goal of ABCT. Ever since Menger's theoretical insights about money up until Mises' first formulation of the theory, the driver of this thought was the need to explain how the world works. Having briefly sketched its historical background, let us look at ABCT as rendered by Roger Garrison in his 2001 book.

The model can be summed up by the graphs presented below. The central notion of ABCT is that of the structure of production (Figure 1). ${ }^{25}$ It is introduced in the place of an aggregate " $\mathrm{K}$ " used in major business cycle models to denote capital stock, as the Austrians judge such lumping together of very different types of capital goods as crude and unjustified, obscuring real mechanism responsible for creation of the cycle. In the construction of the graph (called a

\footnotetext{
${ }^{24}$ This does not mean, of course, that no common sense assumptions are needed at all. One obviously needs to assume existence of more than one human being, existence of money, and so on.

${ }^{25}$ Here one can spot a link to what French - Ladyman (1999) call "structural correspondence between the model and the target". Such correspondence can be understood as full or partial isomorphism, and this interpretation can be employed here as the structure of production in ABCT need not retain all characteristics of the real one, but needs to adequately represent the general features of how supply chains are structured, what time is needed to complete the product, etc. Therefore, general structure of the real world is presumed to be adequately represented here.
} 


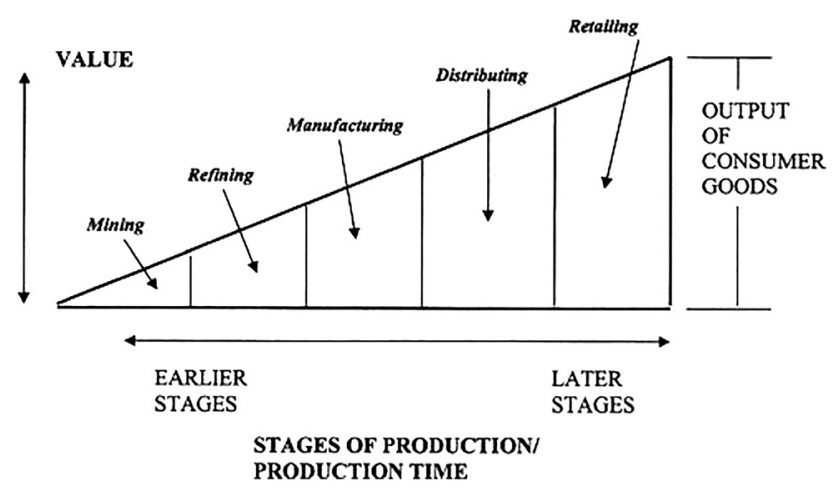

Figure 1. Stages of production in ABCT

Source: Garrison (2001: 47).

"Hayekian triangle"), we can see that there are only a few stages of production, whereas we know that in reality there is much more of them. This is clearly an isolation, as the specific number of the stages is deemed irrelevant to the inquiry into the nature of causal relation involved. It is, then, one of the legitimate methods of isolating causal relationships that is observed here.

Given the notion of the structure of production, the model works as follows. When there is an increase in the supply of savings caused by voluntary decisions of savers to abstain from current consumption (Figure 2), the interest rate drops (lower-right corner, the loanable-funds market diagram). This constitutes a signal for producers that consumers are willing to decrease their consumption in the short run, so there is an incentive to invest in more "roundabout" and, therefore, results in more efficient methods of production. The increase in investment can be seen in the upper-right corner, on the PPF, which shows the distribution of funds available in the economy between consumption and investment. The more money is directed towards investment, the quicker PPF will expand to the right, signifying a quicker growth. The real-world conclusion that is drawn from this is that in the short run a quicker growth requires abstaining from consumption, but this will be more than compensated in the longer run, when PPF will have grown enough. The change in PPF is accompanied by the change in the Hayekian triangle in the upper-left corner. The shift of production processes towards more "roundabout" ones is presented by shortening of the vertical leg (removal of capital from the stages of production close to consumption) and lengthening of the horizontal leg (injection of capital to the stages far from consumption, creation of new stages), resulting in a change of the slope of the hypotenuse. The real-world conclusion that is drawn from this is that what is important for economic growth is not the change in the overall product, but the change in its structure. Below the triangle one can see diagrams picturing changes on labour markets related to respective stages of production - here again is visible a specifically Austrian desire to be as realistic in the description of the economy as possible, as labour markets are disaggregated relatively to, e.g. the Keynesian theory. Yet once again, one also sees how an isolation is manifested in the model - there are only three labour-market diagrams here, while real economies certainly consist of many more, at least partly separated, markets. 


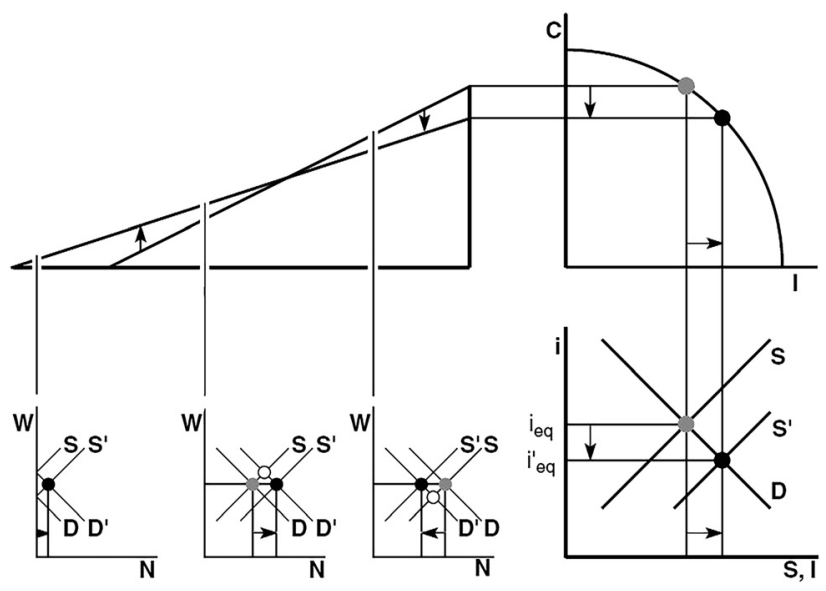

Figure 2. Stable economic growth in ABCT

Source: Garrison (2001: 65).

Figure 3 shows what happens when the interest rate is lowered not because of a voluntary increase in saving, but because of monetary easing on the part of a central bank. Discussion of the mechanics of the model in this case would be very long, ridden with minutiae that are irrelevant to the purpose of this paper, so we will not engage in it here. Suffice it to say that by using similar logic as briefly outlined above, the Austrians come to a real-world conclusion that it is monetary tinkering with the economy by a central bank that bears responsibility for constant industrial fluctuations. Of course, consequences of this conclusion are manifold and very far-reaching. One of them is the postulate to abolish central banking.

Let us now ponder how isolationism helps us in understanding how the model was built and how it works. There are several aspects that need to be touched upon. First of all, note that the whole discussion was done in terms of an already interpreted model. In Section 2, we mentioned that Sugden's and Grüne-Yanoff's accounts postulated that models are interpreted ex post, implying that one can have a discussion of a model in purely formal and uninterpreted terms. But this is not the case here, at least as long as descriptive accuracy is an issue. For the Austrians, driven by their desire to uncover real-world causal relationships, never even tried to express any of their theories and models in the purely formal terms. All diagrams and simplified "worlds" in their writings are meant to really represent parts of the world, to serve as "stand-ins" or surrogates of the finest kind. So, they feel no need to first construct their models and, only then, to give them some interpretation. Interpretation is an integral part of the model in the Austrian economics. This, of course, is an indicator that we are indeed dealing with an isolation (combined with some forms of abstraction) and proper representation (at least as intended by modellers), which gives certain support to the claim that isolationism is descriptively correct about $\mathrm{ABCT} .{ }^{26}$ Second, apart from the already mentioned isolating assumptions, there are

\footnotetext{
${ }^{26}$ We subscribe here to Mäki's (e.g. 1992a) description of differences between isolation and abstraction.
} 


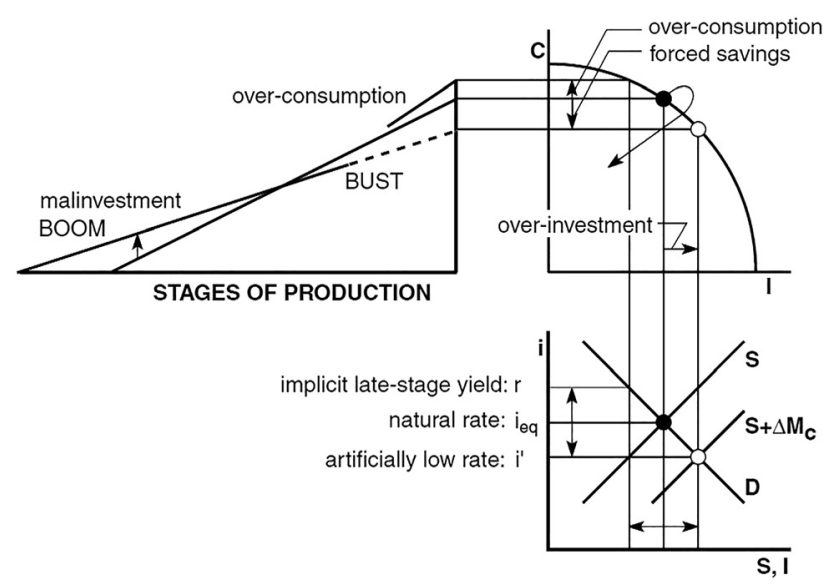

Figure 3. Unstable growth induced by monetary intervention

Source: Garrison (2001: 69).

seemingly many more involved. For example, talking about the interest rate is an obvious simplification, as we know that in an economy many different rates are present. Instead, the Austrians, following Wicksell (2007 (1898)), speak about the "natural" rate of interest. It is either abstraction by omission, if we think that natural rate of interest does exist as a rate distinct from many others, or it is an idealisation, if the natural rate is taken to be, say, some combination of the existing rates. Anyhow, it is a proper way to achieve an isolation. Further, real interest rate (which is the main focus of the model) in the Austrian economics is taken to be solely an expression of people's time preference. The Austrians reduce every traditionally recognised function of money to the medium-of-exchange function and see time preference as the only valid motive for holding money balances, contra mainstream economics (Huerta de Soto 2008, ch. 5). In their view, the precautionary motive, and every other, can be reduced to a manifestation of time preference. But it is important to note that even if one contests such a view, an Austrian can legitimately hold that time preference is all that matters in this specific model, as all movements of curves in diagrams are induced either by changed time preferences of people, or by monetary expansion by a central bank, which is equivalent to a changed money supply without a change in time preference. Therefore, if one subscribes to the view that there is more to money demand than just time preference, one can see the reliance of this model only on time preference as an idealisation (abstraction from other motives) that leads to isolation of the relevant mechanism. Another idealisation can be seen in the loanable-funds graph, where supply and demand curves move and eventually equilibrium is achieved. ${ }^{27}$ This means that the banking sector, which is a means to achieve balance between supply and demand for savings, is abstracted. The Austrians know perfectly well that the specifics of how the sector works matter

\footnotetext{
${ }^{27}$ This is an idealisation in itself, for we know perfectly well that an equilibrium is never achieved in reality, as an economy constantly changes and transforms. It can be treated as some form of theoretical ideal, though.
} 
greatly for the specifics of business cycle (e.g. Garrison 2001; Haberler 1996; Huerta de Soto 2008; Hayek 1931, 1941; Mises 1949; Rothbard 1996). But for the main result of the model (i.e. that business cycle is caused by monetary expansion not backed by a voluntary increase in savings), this specific point is treated as irrelevant. It would seem, then, that the main ingredients of the isolationist approach to model-building are in place. ${ }^{28}$

A clarification is in order before we move on. As noted by some critics of Garrison's model, there are some theoretical and expository problems which render the model incomplete. More specifically, we refer here to Hülsmann's (2001) critique. In Figure 2, the vertical axis of the PPF is in real terms, whereas the vertical axis of the Hayekian triangle measures the value of the output of consumption goods. There is, therefore, no direct correspondence between these two quadrants of the figure, which casts doubts on the chain of reasoning as Garrison would like to have a direct relation between both the axes. Similarly, the horizontal axis of the PPF is in real terms, whereas horizontal axis of the loanable funds market denotes money. Additionally, loanable funds exist presently, whereas the horizontal axis of the PPF shows capital goods produced with the use of these funds during a time period, say, a year. So, the axes do not share a temporal dimension.

But if this renders the model inconsistent, then is it not futile to try and analyse it according to the isolationist paradigm? Would it not contain obvious fictions and constructions? We think there is still a case to be made. First of all, Hülsmann himself does not claim that Garrison's model is inconsistent, but only that the relations between the Hayekian triangle, the PPF, and the graph for the loanable funds market are not completely described by Figure 2. So, more details need to be provided for the relations to become fully understandable. This could be seen as an example of omission that is useful given the expository and pedagogical aims of the modeller. In principle, we think that three quadrants of the graph could be disconnected without any harm to the idea of the model, and then some more sophisticated mechanisms describing the relations between them could be inserted and presented with words. This would mean translating the Garrison model into something closer to the classical expositions of ABCT formulated by Mises or Rothbard. This in turn means that there is a trade-off in the Garrison model - its pedagogical value, missing in the Mises-Hayek model, comes at the expense of sophistication of explanation. ${ }^{29}$ But it does not necessarily follow that analysis of the model in terms of the notion of isolation is wrong-headed. This point is also underscored by our discussion above of the natural rate of interest and time preferences - it did not hinge on the specifics of Garrison's graphs.

But there is an unrelated and significant difficulty in jumping to the conclusion that Garrison's model contains the main ingredients of isolationist approach to model-building - and

\footnotetext{
${ }^{28}$ An important note: it could be the case that some idealisations or abstractions involved in ABCT lead to some kind of overconstraint. This alone would not mean, however, that the isolationist description of the model is not supported. It would just mean that there is a problem in concluding anything about the real-world causality on the basis of ABCT an issue for the model itself, but not for its isolationist description. Further in the text we discuss other difficulties in accounting for ABCT in the isolationist terms.

${ }^{29}$ Here one should also stress that there are differences between visualizations and theoretical models. The visual elements in Fig. 2 are not perfect illustrations of something seen but rather conceptual elements that have to be imagined before they can be put in mathematical formulae. But still these imagined elements are formed in response to economists' reactions to real phenomena, mechanisms, and processes. However, as Morgan (2012) claims in her analysis of the Edgeworth Box, one can be less concerned with logical and mathematical consistency of diagrams than with mathematical tractability of the formal models.
} 
this is our main claim here. ${ }^{30}$ It is important to note that how casually the Austrians speak about causality. The model specifies explicitly what the relevant causal relation is, which runs counter to the usual practice of economists of using causal expressions rather reluctantly (Knuuttila 2009). This is in line with the isolationist claim that one can see in the model how a capacity really works. But how do the Austrians see what the relevant capacity is? In fact, how does any modeller see what the capacity relevant for her study is before she starts to build a model? Isolationism seems to assume that the aim of modelling is to see what is the specific effect of already known, or at least suspected causal mechanism. Of course, one does not start modelling blindly, without at least suspecting what direction one's inquiry could take. It is especially true when one can consult an already established body of knowledge (say, some long-standing theory) which points to the possible research trajectories. Nevertheless, we think that the following story better fits the model we have just discussed.

First, an economist observes an effect, e.g. a recurring business cycle. Then, she constructs (the choice of words is not random here) a model to explore possible causes of the phenomenon, starting with both an initial observation and a set of main principles derived from the existing body of knowledge as well as from the ontological and methodological convictions - in this case, from realism and methodological individualism. This step may include an additional sub-step of showing that all rival theories fail to provide a comparatively satisfying explanation of the phenomenon in question. What is crucial is that this step indeed involves various abstractions and other idealisations, while it does not involve isolation, for the modeller is only looking for causal explanation and not trying to establish the case for an explanation he had, or suspected, beforehand. This means that we cannot speak about deduction at this stage. But there is a catch, so to speak. When an explanation, formulated in causal terms, is found and viewed as "the best" (one can see now that what is proposed here resembles Sugden's abduction ${ }^{31}$ ), researcher (or rather a methodologist, as researchers are rarely so involved in methodological discussion) may try to show that it could be, in principle, a result of isolation, had she known which capacity to isolate beforehand. If this is at least judged possibly in relation to a given model, a deductive, or nearly-deductive link between the model and reality could be established, and so could a relationship of representation.

That even a researcher such as Garrison, who comes from a tradition as committed to scientific realism as the Austrians, engages in what can be interpreted as at least partial modelconstructing, and not full model-isolating, speaks to the need of utilising insights from both methodological strands. For it is clear that ABCT contains various fictions, and not only omissions or abstractions. A simple fact that the Hayekian triangle is indeed a triangle tells a bit about the power of thinking in simple terms, just as Schelling did with his checkerboard model. For sure envisioning of the production process as this triangle was influenced by the goal that was to be achieved - namely, simplicity of exposition. It is impossible to establish whether this particular tool was employed with the specific real-world reference in mind (more in line with

\footnotetext{
${ }^{30}$ So, the discussion in the preceding paragraph was meant only to stress that a potential argument against our analysis that it is obviously wrong, and therefore uninteresting, to analyse Garrison's model in the isolationst terms as it is inconsistent - is incorrect. Then, we proceed with our claim that there are reasons to think isolationism is not the best approach here, but they are not obvious and, therefore, interesting.

${ }^{31}$ Therefore, what is proposed here can be seen as a kind of "rational reconstruction" (Carnap 1967 (1928)) of economic modelling, and not as an account of the minutiae of modelling process.
} 
isolationism) or rather it came first as a handy device, and only then was given this particular interpretation with all its detail (more in line with constructivism). Given the decided realist bent of the Austrians, the former is more probable than the latter. But the sole fact that the constructivist interpretation (interpretation in terms of "fictions") is possible with regard to this and many other aspects of the model discussed here seems telling to us.

The gist of the above argument is that regardless of what the starting point of model-building activity is - and we propose that it rarely is a capacity, that everything rather starts with the effect and the search for explanation is then conducted - if it can be shown that the outcome in the model could be a result of isolation, it should be viewed as compatible with isolationism and, therefore, as a strong and robust result. ${ }^{32}$ Therefore, isolationism should have an important normative role in modelling, even if it seems that its descriptive role is very limited (for it does not account entirely properly even for the properties of $\mathrm{ABCT}){ }^{33}$ If so, and if Cartwright's and others' arguments concerning the difficulties of isolation in economic modelling are correct, then a corollary is that to find robust economic models, one should look outside the mainstream modelling practices, e.g. towards the realistically-minded Austrian school that, arguably, seems to be closer to the isolationist ideal.

\section{CONCLUSIONS}

The discussion at the end of the previous section followed directly from the case study of the $\mathrm{ABCT}$ and hinted at a two-pronged nature of economic modelling. There is a stage in the model-building process at which a researcher is searching for an explanation, drawing on principles and available theories, without necessary connection with the procedure of isolation. This looks more like construction. But there is also a stage in which one may (and, we think, should) connect her result with the world by what could be called "retroactive deduction", i.e., by finding out whether her model is compatible with isolationism, which would give researchers a very high level of confidence in the model.

Obviously, one cannot make sense of this two-pronged nature by using only isolationist or only constructivist account, as they are able to grasp only half of the phenomenon. What is needed is a theory that could encompass the two. A reasonable way of proceeding is to look for a pragmatic theory that shifts focus from the definition of the model itself to the practice of modelling more broadly conceived, as argued by Knuuttila (2009). She rightly notes that the starting point of modelling is often the result that one wants to achieve and not a capacity to isolate. Then she goes on to present a very constructivist-oriented approach that we think is not necessary. But she coins a nice phrase "model-based practice" to capture the fact that modelling involves looking in various directions, not only to the world, and is not easily describable by either "model-target" or "deduction-induction" dyad. According to her, an acceptable model is the one that gives us new inferential links and predictions and leads to acceptance of conclusions

\footnotetext{
${ }^{32}$ This is in line with what Mäki claims in his accounts of modelling where he interprets isolation more in terms of the product (of what model accomplishes) rather than the process (the way in which models are built) (e.g. 2009: 32).

${ }^{33}$ Grüne-Yanoff (2011) also sees a normative role for Mäki's isolationism, although he phrases it differently. This is also compatible with Cartwright's normative approach to methodology of economics, although, as mentioned before, hers is much more dismal outlook. We dare to say it because she does not look at economic heterodoxy.
} 
corroborated in other ways. In accordance with the discussion above, we stress the need for a stronger conception that would include some realism-based linkage to the world. Nevertheless, we agree with the claim that "model-based practice" is a relevant unit of methodological inquiry.

A natural starting point of such theory is a holistic view of human knowledge dating back at least to Quine's Two Dogmas of Empiricism (1951) and Wittgenstein's Philosophical Investigations (1953). Wittgenstein, after retreating from his earlier logistic position expressed in Tractatus Logico-Philosophicus (1922), tried to express all human epistemic activity as a sort of game, which is undeniably an anti-realistic position. Quine (also 1960) proposed a holistic theory of meaning and, consequently, a holistic account of scientific theories, in which every statement is connected with the whole body of theory. His is also a radically pragmatic, antirealistic view, but it does not mean that by drawing inspirations from these works we are forced to abandon any isolationist, deductive model-world link. For these theories spawned a great amount of notable philosophical texts, among which is a statement of "internal realism" by Putnam (1987) and a pragmatist view of epistemology by Goodman (1978) that tries to incorporate some realist notions. This philosophical tradition should, we think, prove very useful in trying to account for a model-theory link on the one hand (as it explicitly deals with the questions such as "What is a construct in the process of acquiring knowledge?"), and for a model-reality link on the other (as many authors, most notably Putnam, insist that their theories deserve the label "realism"). How such theory should look like in detail is an entirely different matter that deserves a number of separate papers. But, at the very least, the focus on the broader model-based practice should allow answering the starting question. Above we postulated constructivism as potentially and descriptively correct about economic models but criticised it from the normative positions. On the other hand, isolationism seems to be descriptively lacking, but important as normative guidance. Therefore, the starting question is a test of this proposition, namely: what is the extent of the problem? Or, in other words: to what extent are economists really constructing in their model-building? To look for the answer, and to go beyond it, one should concentrate at the actual modelling practice, and since "What makes economics a science is models" (Rodrik 2015: 83, 2018), philosophical investigation into the nature of economic models is worth undertaking.

\section{REFERENCES}

Alexandrova, A. (2006): Connecting Rational Choice Models to the Real World. Philosophy of the Social Sciences, 36(2): 173-192.

Apostel, L. (1961): Towards the Formal Study of Models in the Non-Formal Sciences. In: Freudenthal, H. (ed.): The Concept and the Role of the Model in Mathematics and Natural and Social Sciences. Dordrecht: Reidel, pp. 1-37.

Carnap, R. (1938): Foundations of Logic and Mathematics. In: Neurath, O. - Morris, Ch. - Carnap, R. (eds): International Encyclopedia of Unified Science. Vol. 1. University of Chicago Press, pp. 139-213.

Carnap, R. (1967, 1928): The Logical Structure of the World. Pseudoproblems in Philosophy. Berkeley: University of California Press.

Cartwright, N. (1999a): The Dappled World. A Study of the Boundaries of Science. Cambridge University Press. 
Cartwright, N. (1999b): The Vanity of Rigour in Economics. Theoretical Models and Galilean Experiments. Discussion Paper Series, CPNSS.

Cartwright, N. (2007): Economic Models: No Capacities, No Inductions. In: Causal Powers: What Are They? Why Do We Need Them? What Can and Cannot Be Done with Them? London: Centre for Philosophy of Natural and Social Science, LSE, pp. 70-80.

Cartwright, N. (2009): If No Capacities then No Credible Worlds. But Can Models Reveal Capacities? Erkenntnis, 70(1): 45-58.

Cartwright, N. (2010): Models: Parables v Fables. Boston Studies in the Philosophy of Science, 262: 19-31.

Deichsel, S. (2011): Against the Pragmatic Justification for Realism in Economic Methodology. Erasmus Journal for Philosophy and Economics, 4(1): 23-41.

French, S. - Ladyman, J. (1999): Reinflating the Semantic Approach. International Studies in the Philosophy of Science, 13(2): 103-121.

Frigg, R. - Hartmann, S. (2012): Models in Science. Stanford Encyclopedia of Philosophy.

Fullbrook, E. - Caldwell, B. - Davidsen, B. I. - Davis, J. B. - Downward, P. - Guerrien, B. - Hodgson, G. M.

- McFarling, B. R. - Mearman, A.- Ruccio, D.- Staveren, I.- Vromen, J. (eds.) (2009): Ontology and Economics: Tony Lawson and His Critics. New York: Routledge.

Fumagalli, R. (2016): Why We Cannot Learn from Minimal Models. Erkenntnis, 81(3): 433-455.

Garrison, R. (2001): Time and Money: The Macroeconomics of Capital Structure. New York: Routledge.

Goodman, N. (1978): Ways of Worldmaking. Indianapolis: Hackett.

Grüne-Yanoff, T. (2009): Learning from Minimal Economic Models. Erkenntnis, 70(1): 81-99.

Grüne-Yanoff, T. (2011): Isolation is not Characteristic of Models. International Studies in the Philosophy of Science, 25(2): 1-19.

Haberler, G. (1996). Money and the Business Cycle. In: Ebeling, R. M. (ed.): The Austrian Theory of the

Trade Cycle and Other Essays. Auburn: Ludwig von Mises Institute, pp: 37-64.

Hausman, D. (1992): The Inexact and Separate Science of Economics. Cambridge University Press.

Hayek, F. A. (1931): Prices and Production. London: George Routledge and Sons Ltd.

Hayek, F. A. (1941): The Pure Theory of Capital. University of Chicago Press.

Hoover, K. D. (2013): The Role of Hypothesis Testing in the Molding of Econometric Models. Erasmus Journal for Philosophy and Economics, 6(2): 43-65.

Huerta de Soto, J. (2008): Money, Bank Credit, and Economic Cycles. Auburn: Ludwig von Mises Institute. Hülsmann, J. G. (2001): Garrisonian Macroeconomics. The Quarterly Journal of Austrian Economics, 4(3): 33-41.

Hülsmann, J. G. (2007): Mises: The Last Knight of Liberalism. Auburn: Ludwig von Mises Institute.

Knorr Cetina, K. (1998): Constructivism. In: Davis, J. B. - Hands, D. W. - Mäki, U. (eds): The Handbook of Economic Methodology. Cheltenham: Edward Elgar, pp. 75-79.

Knuuttila, T. (2009): Isolating Representations versus Credible Constructions? Economic Modelling in Theory and Practice. Erkenntnis, 70(1): 59-80.

Kovács, O. (2019): Grounding Complexity Economics in Framing Modern Governance. Acta Oeconomica, 69(4): 571-594.

Lawson, T. (1997): Economics and Reality. London and New York: Routledge.

Lawson, T. (2003): Reorienting Economics. London and New York: Routledge.

Lawson, T. (2009): The Current Economic Crisis: Its Nature and the Course of Academic Economics.

Cambridge Journal of Economics, 33: 759-777.

Leijonhufvud, A. (1997): Models and Theories. Journal of Economic Methodology, 4(2): 193-198.

Levy, A. (2012): Models, Fictions, and Realism: Two Packages. Philosophy of Science, 79(5): 738-748. 
Magnani, L. (2001): Abduction, Reason, and Science: Processes of Discovery and Explanation. New York: Kluwer Publishers.

Mäki, U. (1992a): On the Method of Isolation in Economics. Poznan Studies in the Philosophy of Science and the Humanities, 26: 316-351.

Mäki, U. (1992b): The Market as an Isolated Causal Process: A Metaphysical Ground for Realism. In: Caldwell, B. - Böhm, S. (eds): Austrian Economics: Tensions and New Developments. New York: Kluwer Publishers, pp. 35-59.

Mäki, U. (2001): The Way the World Works (www): Towards an Ontology of Theory Choice. In: Mäki, U (ed.): The Economic World View: Studies in the Ontology of Economics. Cambridge University Press, pp. 369-389.

Mäki, U. (2009): Missing the World. Models as Isolations and Credible Surrogate Systems. Erkenntnis, 70(1): 29-43.

Mill, J. S. (1843): A System of Logic. London: Longman.

Mises, von L. (1912): The Theory of Money and Credit. New Haven: Yale University Press.

Mises, von L. (1949): Human Action. New Haven: Yale University Press.

Mises, von L. (1957): Theory and History. New Haven: Yale University Press.

Morgan, M. S. (2012): The World in the Model: How Economists Work and Think. Cambridge University Press.

Morgan, M. S. - Knuuttila, T. (2012): Models and Modelling in Economics. Philosophy of Economics, 4987.

Morrison, M. (2007): Where Have All the Theories Gone? Philosophy of Science, 74(2): 195-228.

Niiniluoto, I. (1998): Induction. In: Davis, J. B. - Hands, D. W. - Mäki, U. (eds): The Handbook of Economic Methodology. Cheltenham: Edward Elgar, pp. 246-249.

Putnam, H. (1987): The Many Faces of Realism. LaSalle: Open Court.

Quine, W. V. O. (1951): Two Dogmas of Empiricism. The Philosophical Review, 60(1): 20-43.

Quine, W. V. O. (1960): Word and Object. Cambridge, MA: MIT Press.

Reiss, J. (2008): Social Capacities. In: Hartmann, S. - Hoefer, C. - Bovens, L. (eds): Nancy Cartwright's Philosophy of Science. New York: Routledge, pp. 265-288.

Rice, C. (2018): Idealized Models, Holistic Distortions, and Universality. Synthese, 196(6): 2795-2819.

Rodrik, D. (2015): Economics Rules. Oxford University Press.

Rodrik, D. (2018): Second Thoughts on Economics Rules. Journal of Economic Methodology, 25(3): 276-281.

Romer, P. (2006): In: Advanced Macroeconomics, McGraw-Hill.

Rothbard, M. N. (1996): Economic Depressions: Their Cause and Cure. In: Ebeling, R. M. (ed.): The Austrian Theory of the Trade Cycle and Other Essays. Auburn: Ludwig von Mises Institute, pp. 65-91.

Schelling, T. (1978): Micromotives and Macrobehavior. New York: Norton.

Sugden, R. (2000): Credible Worlds: The Status of Theoretical Models in Economics. Journal of Economic Methodology, 7(1): 1-31.

Sugden, R. (2009): Credible Worlds, Capacities and Mechanisms. Erkenntnis, 70(1): 3-27.

Wicksell, K. (2007, 1898): Interest and Prices. Auburn: Ludwig von Mises Institute.

Wittgenstein, L. (1922): Tractatus Logico-Philosophicus. London: Kegan Paul, Trench, Trubner \& Co. Ltd. Wittgenstein, L. (1953): Philosophical Investigations. Oxford: Blackwell Publishing. 